\title{
Does anonymity increase response rate in postal questionnaire surveys about sensitive subjects? A randomised trial
}

\author{
M J Campbell, W E Waters
}

\begin{abstract}
Study objective-The aim of the study was to determine whether complete anonymity improves the response rates to a postal questionnaire.

Design-The study derived from a series of postal surveys on AIDS knowledge conducted on six different dates in 1986 and 1987. The sample was randomly divided into two, each group being sent the same questionnaire. One group was informed that the replies were anonymous, the other that they were not. The latter were sent reminders.

Setting-Recipients of the questionnaires were drawn from the Southampton electoral rolls.

Participants-300 people in each survey (total 1800) were sent questionnaires, representing on each occasion a different 1:500 systematic sample.

Results-Response rate was $49 \%$ for the anonymous questionnaires and $51 \%$ for the numbered questionnaires. Reminders boosted the response in the numbered group to $72 \%$.

Conclusions-There is no evidence that anonymity improves response to postal questionnaires, but the use of reminders may do so.
\end{abstract}

The use of mailed, self-administered questionnaires is an effective and inexpensive method of obtaining data from the general population. However, they do not usually have as good a response rate as studies based on personal interviews. $^{1}$ A number of studies have investigated methods of improving the response rate. ${ }^{2-5}$ We have been conducting a sequence of surveys in Southampton to determine the public's level of knowledge of AIDS. Because some of

University of Southampton, South Academic Block, Southampton General Hospital,

Southampton SO9 4XY, United

Kingdom:

Department of

Medical Statistics and

Computing

M J Campbell

Department of

Community Medicine

W E Waters

Correspondence to: Professor Waters

Accepted for publication July 1989

Number of questionnaires returned for all surveys the questions were considered sensitive, we postulated that complete anonymity would improve the response rate. To test this we conducted a randomised trial of anonymous replies versus numbered questionnaires which could be identified and sending out reminders to non-responders.

\section{Methods}

The surveys were conducted on six different dates in 1986 and 1987. For each survey we took a different 1:500 systematic sample of 300 people with a random starting point from the Southampton electoral rolls. The sample was randomly divided into two. A questionnaire was sent to one half, with a stamped addressed envelope and a covering letter stating that the recipient would remain totally anonymous and so could not be identified. To the other half, the letter pointed out that the questionnaire was numbered and stated that, if no reply was received, a reminder would be sent. The reminder, with a second copy of the questionnaire and another stamped addressed envelope, was sent to the non-responders three weeks after the original.

\section{Results}

The results (table) show that there was no difference in the response rates between the anonymous questionnaires and the reply to the first numbered questionnaires $\left(\chi^{2}=0.45, \mathrm{df}=1\right.$, $p>0.5)$. It is noticeable that the response rates to both fell to a very similar degree in July and December 1987, possibly because the public were losing interest in the AIDS issue. The response rate to the reminder were in general similar to the response rates to the first questionnaire, except in December 1986 and March 1987, when the response rates to the original questionnaire were

\begin{tabular}{|c|c|c|c|c|c|c|c|}
\hline \multicolumn{3}{|c|}{ Anonymous questionnaires } & \multicolumn{5}{|c|}{ Numbered questionniares } \\
\hline Date & $\begin{array}{l}\text { Initial } \\
\text { mailing } \\
\text { (out of 150) }\end{array}$ & $\%$ & $\begin{array}{l}\text { Initial } \\
\text { mailing } \\
\text { (out of 150) }\end{array}$ & $\%$ & $\begin{array}{l}\text { After } \\
\text { reminder }\end{array}$ & $\begin{array}{l}\text { Repsonse } \\
\text { rate of } \\
\text { reminders } \\
(\%) \\
\end{array}$ & $\begin{array}{l}\text { Response } \\
\text { rate with } \\
\text { reminders } \\
\left(0_{0}^{0}\right) \\
\end{array}$ \\
\hline $\begin{array}{l}\text { Feb } 86 \\
\text { Jun } 86 \\
\text { Dec } 86 \\
\text { Mar } 87 \\
\text { Jul } 87 \\
\text { Dec } 87\end{array}$ & $\begin{array}{l}68 \\
76 \\
86 \\
87 \\
69 \\
59 \\
\end{array}$ & $\begin{array}{l}45 \\
51 \\
57 \\
58 \\
46 \\
39\end{array}$ & $\begin{array}{l}83 \\
68 \\
96 \\
86 \\
68 \\
58 \\
\end{array}$ & $\begin{array}{l}55 \\
45 \\
64 \\
57 \\
45 \\
39 \\
\end{array}$ & $\begin{array}{l}36 \\
41 \\
24 \\
24 \\
33 \\
32\end{array}$ & $\begin{array}{l}54 \\
50 \\
44 \\
38 \\
40 \\
35\end{array}$ & $\begin{array}{l}79 \\
73 \\
80 \\
73 \\
67 \\
60 \\
\end{array}$ \\
\hline $\begin{array}{l}\text { Total } \\
\text { (out of } \\
900 \text { ) }\end{array}$ & 445 & 49 & 459 & 51 & 190 & 43 & 72 \\
\hline
\end{tabular}


high. The net result is that guaranteed anonymity did not increase the response rate, but use of the reminders boosted the response rate from a poor $50 \%$ to a more respectable $\mathbf{7 2} \%$.

\section{Discussion}

An American survey that asked questions on sexual behaviour achieved an $85 \%$ response rate on a small sample by first telephoning the individuals concerned and explaining the reason for the survey and the method by which they had been chosen. ${ }^{4}$ In Britain this approach has not often been used because of the lower percentage of telephone owners. One of our covering letters explicitly pointed out the number on the questionnaire and mentioned the fact that a reminder would be forthcoming. This may have improved the response rate more than if no mention of the reminder has been included. In a subsequent survey of hospital workers, we did not mention the possibility of a reminder in the first letter, but stated that the results would be "confidential". A number of persons who received the reminder protested that the fact that we could identify whether they had replied meant that they had been misled as to the nature of the confidentiality. In surveys of this nature we would recommend a reminder, with a statement in the original covering letter that a reminder would be forthcoming if no reply is received from the first questionnaire.

1 Bennett AE, Ritchie I. Questionnaires in medicine. London: Oxford University Press, 1975.

2 Scott C. Research on mail surveys. I Roy Stat Soc (Series A) 1961; 124: 143-205.

3 Newland CA, Waters WE, Standford AP, Batchelor BG. A study of mail survey method. Int $\mathcal{F}$ Epidemiol 1977; 6: 65-7.
Rosenfield AA. Increasing questionnaire response. $A m \dot{\mathcal{F}}$ Rosenfield AA. Increasing ques
Psychiatry 1979; 136: 1480-1.

5 Mortagy AK, Howell JBL, Waters WE. A useless raffle. I Epidemiol Community Health 1985; 39: 183-4. 